\title{
MATERNIDADE HIGIÊNICA: NATUREZA E CIÊNCIA NOS MANUAIS DE PUERICULTURA PUBLICADOS NO BRASIL
}

\section{Hygienic delivery: nature and science in child care manuals published in Brazil}

Ana Laura Godinho Lima*

\begin{abstract}
RESUMO
Neste texto pretende-se discutir as seguintes questões: Quais as principais motivações dos pediatras que se dispuseram a escrever manuais de puericultura nas primeiras décadas do século XX? Como se procurou tornar acessíveis às mães os conhecimentos científicos sobre a maternidade e os cuidados com os bebês? Como os pediatras procuraram orientar as mulheres em relação à gestação, ao parto e aos cuidados com seus bebês? Para compreender essas questões, parte-se de uma análise histórica de manuais de puericultura destinados às mães e publicados no Brasil entre 1918 - quando foram reunidas em um livro as lições de Higiene Infantil proferidas no Instituto de Proteção e Assistência à Infância pelo Dr. Moncorvo Filho - e 1968, ano do surgimento da revista Pais \& Filhos, que promoveu uma grande divulgação dos conhecimentos sobre a puericultura no Brasil. A análise baseia-se em textos de Michel Foucault e Nikolas Rose sobre a "governamentalidade" e a "biopolítica".
\end{abstract}

Palavras-chave: maternidade; manuais de puericultura; educação.

* Doutora em Educação, professora da Escola de Artes, Ciências e Humanidades da Universidade de São Paulo - USP. 


\begin{abstract}
This paper intends to discuss the following issues: Which were the pediatrician's main motivations in writing baby books during the first decades of the XX century? How did doctors try to make scientific knowledge about maternity and child rearing accessible to the mothers? How did pediatricians seek to provide women with orientations on pregnancy, birth and caring for their babies? In order to comprehend these issues, this study is based on a historical analysis that focuses on baby books published in Brazil between 1918 - when Doctor Moncorvo Filho's lessons on Child Hygiene taught at the Institute for the Protection and Assistance for Children were joined in a book - and 1968, when the journal Parents and Children, which promoted a major spreading of knowledge on child rearing in Brazil. The analysis is based in Michel Foucault and Nikolas Rose's texts on governmentality and "biopolitics".
\end{abstract}

Key words: maternity; baby books; education.

\title{
Introdução
}

Neste texto, pretende-se discutir as seguintes questões: Quais as principais motivações dos pediatras que se dispuseram a escrever manuais de puericultura nas primeiras décadas do século XX? Como se procurou tornar acessíveis às mães os conhecimentos científicos sobre a maternidade e a puericultura? Como os pediatras procuraram orientar as mulheres em relação à gestação, ao parto e aos cuidados com seus bebês? Para compreender essas questões, parte-se de uma análise histórica de manuais de puericultura destinados às mães e publicados no Brasil entre 1918 - quando foram reunidas em um livro as lições de Higiene Infantil proferidas no Instituto de Proteção e Assistência à Infância pelo Dr. Moncorvo Filho - e 1968, ano do surgimento da revista Pais \& Filhos ${ }^{1}$, que promoveu uma grande divulgação dos conhecimentos sobre a puericultura no Brasil. A análise baseia-se em textos de Michel Foucault e Nikolas Rose sobre a governamentalidade e a biopolítica.

1 Pais \& Filhos, São Paulo, Bloch/Manchete, 1968. 
Esta investigação partilha da perspectiva que é comum aos estudos sobre a governamentalidade, segundo a qual se considera que não apenas o Estado, mas múltiplos agentes e instituições podem exercer funções de governo. Entende-se que o governo corresponde a um conjunto de ações que tem por objetivo "conduzir a conduta" de uma pessoa ou grupo ou efetuar uma "correta disposição das coisas de que se assume o encargo para conduzilas a um fim conveniente" 2 . Outra característica importante atribuída ao governo diz respeito à maneira como se procura basear seu exercício em conhecimentos a respeito das coisas e pessoas que toma como alvo.

Para Foucault, um dos fatores decisivos para o desenvolvimento da arte do governo foi a descoberta da população como uma unidade específica de governo e irredutível à família, que era considerada a unidade social básica até o século XVIII na Europa ocidental. A população e os seus fenômenos próprios, os quais podiam ser estudados mediante o emprego das técnicas estatísticas: taxas de natalidade e mortalidade, movimentos migratórios, expectativa de vida e os fatores que poderiam interferir em todos esses índices passaram a constituir um campo privilegiado da atenção e da intervenção do governo. O objetivo do governo passou a ser prioritariamente o de defender a vida e o bem-estar da população, na medida em que isso fosse considerado importante para o crescimento e a segurança do Estado. À modalidade de poder exercido sobre as dinâmicas populacionais, Foucault denominou "biopolítica". Como parte do processo de governamentalização do Estado, o biopoder surge não para substituir a soberania, mas para complementá-la e atualizá-la. Assim, se durante a Idade Média a soberania funcionava de acordo com uma lógica dedutiva, pela qual o soberano procurava retirar dos seus súditos aquilo que eles poderiam oferecer-lhe - impostos, trabalho ou a própria vida -, com as novas teorias sobre o governo, essa lógica dedutiva será substituída por uma produtiva, para a qual interessará ampliar o potencial da população, sua saúde, sua riqueza, e mesmo sua felicidade, pois tudo isso passará a ser visto como formas de fortalecer o Estado. Isso não significará a destruição dos instrumentos e das instituições próprias da soberania, apenas a sua ressignificação:

2 PERRIÈRE, G. apud FOUCAULT, M. A Governamentalidade. In: poder. 12. ed. Rio de Janeiro: Graal, 1996. p. 282. 
Todas as formas modernas de governo do Estado precisam ser entendidas como tentativas de articular um biopoder, interessado em promover as vidas de uma população através da aplicação da norma, com os elementos de uma soberania transformada, que mira sujeitos em um território e cujo instrumento é a lei. ${ }^{3}$

Numa perspectiva biopolítica, promover a saúde e o bem-estar dos diferentes segmentos da população consiste numa missão importante do governo, na medida em que um conjunto de cidadãos bem constituídos representa um valioso recurso que pode ser posto a serviço do Estado, enquanto uma população doente concorre para debilitar a nação. Sendo assim, e considerando-se que as intervenções nas formas de vida da população requerem não apenas conhecimentos estatísticos sobre as dinâmicas e os movimentos populacionais, mas também sobre o corpo e a saúde dos indivíduos, o recurso do governo à medicina tornou-se indispensável.

No caso brasileiro, a medicina alcançou um desenvolvimento expressivo ao longo do século XIX e elegeu como uma de suas questões prioritárias a educação, na medida em que se passou a considerar que o principal objetivo dos médicos deveria ser a prevenção da doença, o que exigiria simultaneamente a produção de saberes sobre a cidade e a população e a intervenção do médico no espaço social. Gondra afirma que foi nesse período que surgiram duas das características mais marcantes da medicina: a inserção dos médicos na sociedade, a qual se tornaria alvo das práticas e das reflexões da medicina, e, como decorrência, a atuação dos médicos como um sustentáculo do poder político. Foram sobretudo os médicos higienistas que se ocuparam dos objetos sociais e se dedicaram a educar a população, elegendo famílias e professores como os "principais destinatários das prescrições médicas"4.

A leitura dos manuais de puericultura sobre os quais incide esta investigação permite afirmar os seus ensinamentos pretendia exercer uma função biopolítica. Na introdução ao manual intitulado Noções de puericultura para as mães e para as escolas, por exemplo, Almeida Junior e Mario Mursa entendiam que o ensino da puericultura deveria ser encarado como uma questão política de máxima importância, como demonstra o texto a seguir:

3 DEAN, M. Governmentality: power and rule in modern society. London/ Thousand Oaks/ New Delhi: Sage Publications, 1999. p. 102.

4 GONDRA, J. G. Medicina, higiene e educação escolar. In: LOPES, Eliane M. T. et al. 500 anos de educação no Brasil. 2. ed. Belo Horizonte: Autêntica, 2000. p. 525. 
Serão as mães culpadas? Ou o delicto é dos que, podendo, não tratam de instrui-las? O Estado julga-se no dever de procurar, até no recesso das mattas, o futuro cidadão, e, seja ou não do agrado deste, ensinar-lhe a garatujar a assignatura, na acta eleitoral, para que a soberania popular se manifeste em toda a plenitude; mas esquece de divulgar, entre as mães actuaes ou futuras, os principios que fariam florescer criaturas sadias e robustas, que enriqueceriam a nação com energias de toda especie, augmentando-lhe a efficiencia physica e moral e poupando-lhe mais de metade do sacrificio prematuro de vidas. Quem toma a si velar pela validez publica, quem pune as fraudes contra a saude collectiva, quem decreta a vaccinação obrigatória, deve, sem sombra de dúvida, tornar compulsorio o apprendizado da puericultura. ${ }^{5}$

\section{Razões de ser dos manuais de puericultura}

Os manuais destinados a oferecer às famílias conselhos sobre as maneiras mais adequadas de cuidar das crianças não foram inventados pelos médicos higienistas. Desde o século XVI uma série de manuais e tratados de costumes procurou registrar os princípios da boa criação dos filhos. O surgimento dessa literatura está ligado ao fato de que, nesse período, houve uma intensa valorização da infância. Entendia-se que, transformando a criança, seria possível transformar as sociedades; corrigindo-se os defeitos na educação dos pequenos, reformarse-ia toda a humanidade. As reflexões sobre esse tema receberam contribuições de intelectuais renomados, como Erasmo de Rotterdam, que publicou, em 1530, De civilitate morum puerilium, e John Locke, autor de Some Thoughts concerning Education, de $1693 .^{6}$

O tratado escrito por Erasmo constituiu uma das fontes principais nas quais se baseou Norbert Elias ao escrever O processo civilizador. ${ }^{7}$ Tendo em vista o sucesso alcançado por De civilitate morum puerilium, Elias afirma que havia realmente um grande interesse da sociedade da época por orientações relativas ao ensino dos bons costumes às crianças.

5 ALMEIDA JUNIOR, A; MURSA, M. Noções de puericultura para as mães e para as escolas. São Paulo: Instituto D. Anna Rosa, 1927. p.V-VI.

6 VENÂNCIO, R. P.; RAMOS, J. M. Apresentação. In: GUSMÃO, A. Arte de criar bem os filhos na idade da puerícia. Apres. e notas de R. P. Venâncio e J. M. Ramos. São Paulo: Martins Fontes, 2004. p. X-XI. 1994. v. 1.

ELIAS, N. O processo civilizador: uma história dos costumes. Rio de Janeiro: Zahar, 
Esta obra evidentemente tratava de um tema que estava maduro para discussão. Teve imediatamente uma imensa circulação, passando por sucessivas edições. Ainda durante a vida de Erasmo - isto é, nos primeiros seis anos após a publicação - teve mais de 30 reedições. No conjunto, houve mais de 130 edições, 13 das quais em data tão recente quanto o século XVIII. Praticamente não tem limites o número de traduções, imitações e seqüências. ${ }^{8}$

Esses primeiros compêndios tinham um caráter predominantemente social e moral e sua preocupação maior era com a boa formação das crianças para o convívio em sociedade, não tanto com sua constituição física. Mesmo quando, a partir da segunda metade do século XVIII, a família se tornou "alvo de um grande empreendimento de aculturação médica" na Europa e começaram a surgir diversos manuais sobre os cuidados higiênicos que se deveria ter com as crianças e, sobretudo, com os bebês ${ }^{9}$, a tradição anterior não foi imediatamente abandonada. Os compêndios morais passaram a coexistir com os novos livros de conselhos higiênicos e apenas a longo prazo os tratados médicos se tornaram mais importantes do que os de caráter predominantemente moral. ${ }^{10}$ Como se explica, no entanto, o surgimento desses manuais médicos sobre os cuidados que se deveria ter com as crianças, a partir do século XVIII? Para Foucault, a medicalização da família com o objetivo de proteger a saúde das crianças relaciona-se ao fato de que a saúde e o bem-estar da população aparecem como sendo um novo objetivo do poder político na Europa ocidental nessa época. Se, no início da Idade Média, o Estado exercia apenas as funções de gerir a guerra e a paz, no final dessa época passou a desempenhar mais duas funções: a de garantir a manutenção da ordem e a de promover o enriquecimento. E, a partir do século XVIII, surge ainda uma terceira função: a de cuidar da saúde da sociedade. Embora se possa considerar que a atenção para a saúde tenha relação com o objetivo do governo de preservar a força de trabalho, Foucault entende que se trata de um problema mais amplo, ligado ao aumento da densidade demográfica e à necessidade de governar um número crescente de pessoas vivendo no mesmo espaço, fenômeno que culminou no surgimento da "população" como unidade nova de governo. A população

8 ELIAS, op. cit., p. 68.

9 FOUCAULT, M. A política da saúde no século XVIII. In: 12. ed. Rio de Janeiro: Graal, 1996. p. 200. Microfisica do poder.

10 VENÂNCIO; RAMOS, op. cit., p. XIV. 
“com suas variáveis de números, de repartição espacial ou cronológica, de longevidade e de saúde - não somente como problema teórico, mas como objeto de vigilância, análise, intervenções, operações transformadoras, etc." 11 Uma das características da biopolítica que se desenvolveria daí por diante foi descrita pelo autor como "o privilégio da infância e a medicalização da família" indivíduos desde a infância, o estudo dos fatores favoráveis e deletérios ao crescimento saudável e a intervenção na esfera familiar com o objetivo de assegurar um ambiente propício à sobrevivência e evolução infantil:

\begin{abstract}
São codificadas, então, segundo novas regras - e bem precisas - as relações entre pais e filhos. São certamente mantidas, e com poucas alterações, as relações de submissão e o sistema de signos que elas exigem, mas elas devem estar regidas, doravante, por todo um conjunto de obrigações que se impõe tanto aos pais quanto aos filhos: obrigações de ordem física (cuidados, contatos, higiene, limpeza, proximidade atenta); amamentação das crianças pelas mães; preocupação com um vestuário sadio; exercícios físicos para assegurar o bom desenvolvimento do organismo: corpo a corpo permanente e coercitivo entre os adultos e as crianças. ${ }^{13}$
\end{abstract}

Fenômeno análogo ocorrido no Brasil a partir de meados do século XIX foi analisado por Jurandir Freire Costa na obra Ordem médica e norma familiar. Segundo esse autor, por meio da atuação dos médicos higienistas, o papel dos pais transformou-se no decorrer do processo de medicalização da família. O pai, que na família tradicional era proprietário dos filhos, passou a desempenhar outra função, a de tutor de "filhos cujo verdadeiro proprietário era a nação, o país"14.

Em sua "Pequena crônica da puericultura e pediatria brasileiras"15, José Martinho da Rocha afirma que um dos precursores da puericultura no Brasil foi o doutor Francisco de Mello Franco, que publicou em Lisboa, no ano de 1790, o Tratado de educação fisica dos meninos. Segundo Rocha, essa publicação continha "preceitos pioneiros que são válidos até hoje" e era

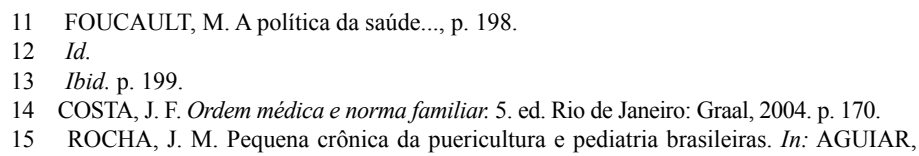
A.; MARTINS, E. M. (Eds.). História da pediatria brasileira: coletânea de textos e depoimentos. Rio de Janeiro: Sociedade Brasileira de Pediatria/Nestlé, 1996. 
muito superior ao primeiro guia materno surgido no Brasil, intitulado A guia médica das mães de família (1843). ${ }^{16}$ No entender de Martinho da Rocha, esse primeiro compêndio brasileiro, escrito por J. B. A. Imbert, divulgava "valiosos conselhos de higiene infantil, embora de mistura com muitas noções errôneas"17. Rocha não apresenta informações sobre o autor, mas a data de publicação da Guia médica indica que os manuais de puericultura precederam a própria pediatria brasileira em mais de quatro décadas. Segundo Walter Telles, essa especialidade médica surgiu em nosso país apenas no ano de 1882, quando foi criado o primeiro "curso de clínica das moléstias das crianças" no Serviço da Policlínica Geral do Rio de Janeiro, por iniciativa de Carlos Arthur Moncorvo de Figueiredo. Segundo Telles, no período anterior,

\footnotetext{
as escassas noções ficavam por conta da cadeira de Partos, cujo primeiro titular, Francisco Julio Xavier, diplomado pela Faculdade de Medicina de Paris, ao ocupar a cátedra, em 1833, proferiu lição inaugural sobre "cuidados e socorros que se devem prestar aos meninos por ocasião de seu nascimento e sobre as vantagens do aleitamento maternal". ${ }^{18}$
}

Por outro lado, de acordo com Jurandir Freire Costa, desde meados do século XIX o tema da mortalidade infantil preocupava as instituições e os profissionais dedicados à medicina. Já em 1846, a Academia Imperial de Medicina propusera aos seus membros uma série de questões relativas a esse problema. As respostas indicavam que, na percepção dos doutores, as principais causas da mortandade das crianças estava relacionada à negligência dos pais, sobretudo ao descaso com os filhos ilegítimos e à "falta de educação física, moral e intelectual das mães"19. A partir dessas constatações, os médicos higienistas passaram a combater com energia as condutas das famílias tradicionais consideradas nocivas à saúde das crianças: o antigo hábito dos senhores de escravos de exigir que suas escravas abandonassem seus filhos na Casa dos Expostos para poderem ser alugadas como amas de leite e também o hábito das mulheres de elite de contratar amas de leite para,

16 ROCHA, Pequena crônica da puericultura ..., p. 164.

17 ROCHA, Introdução à história da puericultura no Brasil. Rio de Janeiro: Nestlé, 1947. p. 49.

18 TELLES, W. Um século de pediatria. In: AGUIAR, A.; MARTINS, E. M. (Eds.). História da pediatria brasileira: coletânea de textos e depoimentos. Rio de Janeiro: Sociedade Brasileira de Pediatria/Nestlé. 1996. p. 147.

19 TEIXEIRA, J. M. Causas da mortalidade das crianças no Rio de Janeiro. Rio de Janeiro: Brown \& Evaristo, 1876. p. 269-270, apud COSTA, op.cit., p. 164. 
dessa maneira, eximirem-se da tarefa de amamentar seus próprios filhos.

Jurandir Freire Costa esclarece, no entanto, que a principal motivação dos médicos ao condenar essas práticas não era a defesa do direito das crianças filhas de escravas aos cuidados maternos, mas sim a garantia de boas condições de desenvolvimento para os bebês das famílias ricas. Entendiase que uma escrava privada à força do contato com seu próprio filho não poderia dar uma boa ama, não apenas porque, deprimida e de má-vontade, poderia se tornar cruel com a criança pela qual se tornaria responsável, mas também porque se acreditava que os abalos morais podiam ter como efeito "estragar" o leite com que iria alimentar o bebê de sua senhora. ${ }^{20}$ Ao responsabilizar as famílias pelo sofrimento e a morte das crianças, os médicos conquistaram o espaço doméstico, transformando-o em campo privilegiado para administrar as condições de vida da população infantil.

Os manuais de puericultura consistiam em uma das estratégias empregadas pelos pediatras para levar os seus ensinamentos para além dos seus consultórios. Serviam como um suporte de informações particularmente útil, na medida em que, estando sempre à mão, podiam ser consultados no exato momento em que surgisse uma dúvida em relação ao cuidado com o bebê. A partir do início do século XX, além de serem destinados às mulheres grávidas, esses compêndios passaram a ser redigidos também como material didático dos cursos de puericultura oferecidos nas Escolas Normais. Apresentavam, portanto, sempre um propósito educativo.

Num cenário ideal, as jovens estudariam puericultura durante $o$ curso normal, sob a supervisão de um professor, numa fase da vida em que ainda eram solteiras e a perspectiva dos filhos era mais ou menos remota. Levariam em conta os ensinamentos da eugenia veiculados na disciplina ao decidirem se casar. Mais tarde, durante a gravidez, retomariam seus manuais, agora com maior interesse, antecipando as características de seu filho e a rotina de cuidados com o bebê. Conservariam ainda os seus manuais de puericultura para consultas ocasionais, nos intervalos entre as visitas periódicas ao médico.

Esses livros foram, assim, uns recursos entre outros empregados pelos pediatras higienistas com o objetivo de difundir os princípios de puericultura. Dirigiam-se, sobretudo, às mulheres educadas, pertencentes às camadas mais favorecidas da população. Quando redigidos para serem 
estudados nos Cursos Normais, tinham em vista não apenas a mãe, mas também a professora. Nesse caso, esperava-se que as mestras, ao incutir bons hábitos de higiene em seus alunos, exercessem também uma influência salutar na família das crianças, as quais passariam a cobrar de suas próprias mães a observância dos princípios estudados na escola. Sendo assim, fosse pela via mais direta das mães ou mais indireta da influência exercida pela professora da criança, o que se tinha em vista era intervir na rotina familiar.

\section{Modalidades de divulgação dos conhecimentos cientificos da puericultura entre as mães}

Além dos manuais para as mães das camadas mais favorecidas da população, dos cursos de puericultura nas Escolas Normais e do atendimento nos consultórios, os pediatras procuraram ainda divulgar seus conhecimentos para uma população mais ampla, em palestras proferidas pelo rádio, em colunas redigidas nos jornais e por meio de sua participação em instituições que tinham como propósito prestar assistência às pessoas necessitadas.

Um exemplo importante de instituição de assistência que passou a funcionar na passagem do século XIX para o século XX foi o Instituto de Proteção e Assistência à Infância do Rio de Janeiro (IPAI-RJ). Fundado pelo médico e filantropo Arthur Moncorvo Filho ${ }^{21}$ em 24 de março de 1899, em 1929 o instituto já possuía 22 filiais em todo o país, 11 delas com creche. ${ }^{22}$ Entre os objetivos dessa instituição, estava o de proteger as crianças pobres, doentes, defeituosas, maltratadas e moralmente abandonadas. Segundo Kuhlmann Jr., o lema da instituição era "Infantes tuendo, pro pátria laboramus (Quem ampara a infância, trabalha pela pátria)"’23. O IPAI também se dedicava a difundir noções de higiene infantil às famílias pobres e prestava assistência às mulheres grávidas, além de incentivar $\mathrm{o}$ aleitamento materno e a vacinação

21 Moncorvo Filho integrou a primeira geração de pediatras formados pela Policlínica Geral do Rio de Janeiro, fundada por seu pai, Carlos Arthur Moncorvo de Figueiredo.

22 KUHLMANN JR., M. Infância e educação infantil: uma abordagem histórica. Porto Alegre: Mediação, 1998.

23 Ibid., p. 96. 
das crianças. A esse respeito, é preciso registrar que os doutores filantropos não dispensaram o auxílio das senhoras da sociedade, que, de diversas maneiras, foram encorajadas a envolver-se nas atividades de assistência. Assim, segundo Ana Maria Magaldi, pode-se falar em uma dupla aliança entre os médicos e as mulheres bem nascidas, efetivada tanto no espaço do lar quanto no domínio da caridade. No segundo cenário, "aquelas mulheres, caracterizadas por seu 'coração depositário de infinita bondade' eram chamadas a exercer ações de benemerência na direção das famílias e, em especial, das crianças pobres e, segundo o que se pode perceber, responderam com empenho à convocação." 24 A autora refere-se à cerimônia de inauguração de uma unidade do IPAI, em que Moncorvo Filho incluíra em seu discurso a seguinte nota de agradecimento às suas dedicadas colaboradoras:

Foram de fato as senhoras que, na exuberância de suas dedicações, quando os óbices atingiram ao quase insuperável, quando próximo de nós sentíamos a exaustão e o esgotamento, nos emprestavam o ânimo regenerado, dando com o seu edificante exemplo, com a sua ação a um tempo enérgica e carinhosa a prova do quanto valem o alívio das dores humanas, a transformação sutil da lágrima no sorriso, do desalento na esperança, tudo isto sempre com o encanto que possui a mulher patrícia, a Filha dedicadíssima, a Esposa inexcedível, a Genitora incomparável. ${ }^{25}$

Nesse elogio à mãe brasileira, o autor referia-se àquelas que deveriam servir de exemplo à maioria, geralmente caracterizadas pelos autores dos manuais consultados como sendo muito afetivas, mas simultaneamente muito ignorantes dos princípios da higiene infantil, como se verá a seguir.

Conforme já se mencionou, o mais antigo dos manuais considerados nesta pesquisa consiste na reunião das lições proferidas por Moncorvo Filho no IPAI. Em sua introdução a Hygiene infantil, o autor explicava que, ao criar o curso, tivera a intenção de imitar a iniciativa patriótica de colegas que atuavam em diversos outros países, ainda inéditas no Brasil. Preocupara-se ainda em formular

24 MAGALDI, A. M. B. M. Receitas de civilização: a aliança médico-mulher e a educação da família brasileira na Primeira República. Saúde, Sexo e Educação, Rio de Janeiro, IBMR, v. 36, p. 6-17, 2005.

25 MONCORVO FILHO, A. Pela infância, tudo! Discurso pronunciado em 14/3/1920 na solenidade de inauguração do IPAI de Petrópolis. Rio de Janeiro: Bernard Frères, 1920, p. 3, apud MAGALDI, op. cit., p. 14. 
suas orientações em uma "linguagem clara e ao alcance de todos" "26, demonstrando assim sua preocupação em atingir as mães pobres e iletradas. Mostrava-se lisonjeado com a acolhida do público, formado, segundo ele, por "representantes de todas as classes sociais de ambos os sexos" ${ }^{27}$, de modo que decidira atender às solicitações feitas para que as conferências fossem publicadas.

Em seus manuais de puericultura, os médicos ansiavam por compartilhar com suas leitoras tudo quanto sabiam sobre a higiene infantil, de modo a fazer delas suas aliadas na luta pela prevenção das doenças e, sobretudo, na batalha contra a mortalidade infantil. Acreditava-se que uma de suas principais causas era justamente a ignorância dos preceitos da puericultura, como demonstra o seguinte trecho da Cartilha das mães:

Quantos erros a corrigir, quanta desgraça evitável! Só é possível melhorar a situação lamentavel da mortalidade das crianças entre nós pelo ensino systematico da hygiene infantil a todas as moças, para que ellas, além de mães, se façam boas enfermeiras dos próprios filhos. ${ }^{28}$

Tendo em vista que quase sempre os pediatras eram homens bem mais velhos, muitas vezes professores, pronunciando-se com base nos conhecimentos científicos adquiridos ao longo de sua formação nas faculdades de medicina e em sua vasta experiência clínica, seria talvez de esperar que esses não encontrassem a menor resistência por parte de suas jovens leitoras em seguir suas recomendações. No entanto, a análise dos manuais permite observar que os doutores precisavam empregar diversas estratégias para combater aquelas que eram as suas principais adversárias: as mulheres mais vividas, representadas pela figura da avó, da comadre, da vizinha e outras "entendidas" que costumavam auxiliar as novatas com base em suas próprias experiências como mães. Os doutores recorriam a autores estrangeiros, a dados estatísticos apresentados na forma de gráficos e tabelas, a fotografias e a outros recursos para demonstrar racionalmente os perigos aos quais as mães expunham seus filhos sempre que deixavam de seguir as recomendações médicas para dar ouvidos às avós, associadas nos livros a superstições e práticas ultrapassadas.

p. 163.

26 MONCORVO FILHO, Hygiene infantil. Rio de Janeiro: Imprensa Nacional, 1918.

27 Id.

28 ROCHA, J. M. Cartilha das mães. 7. ed. Rio de Janeiro: Civilização Brasileira, 1939. 
Os autores dos manuais depositavam uma enorme confiança na ciência e nos procedimentos por ela recomendados para a formação de indivíduos saudáveis e a organização de uma sociedade próspera. A conquista desses objetivos, no entanto, dependia tanto da eugenia quanto da puericultura. Para os médicos, não se devia esperar o nascimento do bebê para iniciar os cuidados. Era preciso começar antes mesmo da concepção. A eugenia era a ciência que orientaria as mães na escolha ideal do parceiro, que não deveria ser deixada às inclinações do instinto sexual, mas deveria basear-se na razão. ${ }^{29}$ Uma maneira diferente de ver as coisas pode ser encontrada no Guia para criar o bebê, do Dr. Martinho da Rocha. Escrito em 1951, afirmava que a escolha instintiva do parceiro tendia a dar melhores resultados do que a escolha por conveniência. Embora não se encontre no texto a justificativa dessa orientação, pode-se inferir o raciocínio do autor: a escolha motivada pela "inclinação instintiva" atenderia a critérios de juventude e beleza, portanto a qualidades biológicas superiores para a reprodução, enquanto os casamentos de conveniência tenderiam a privilegiar a condição social do parceiro e não seus atributos genéticos. Não fosse assim, pareceria estranho que no mesmo manual o autor se manifestasse favoravelmente à obrigatoriedade do exame pré-nupcial e afirmasse que a liberdade dos indivíduos em escolher o seu par deveria ser "logicamente limitada pelos direitos do menino que irá nascer"30. De modo que as tendências naturais eram valorizadas apenas na medida em que fossem consideradas úteis para os objetivos estabelecidos pelos médicoscientistas. A esse respeito, Jurandir Freire Costa afirma ainda:

A relevância dada ao "amor físico" no casamento atendia a vários objetivos higiênicos. Em primeira instância, buscava-se fixar a sexualidade masculina na relação com a esposa, livrando-a da prostituição. Com isto, procurava-se debelar as doenças venéreas e prevenir o nascimento de filhos sifilíticos. Em segunda instância, tentava-se estimular a vida sexual das mulheres, cuja ausência ou debilidade comprometiam a saúde física dos filhos e a moral do casal. Neste sentido é que se recriminou veementemente o casamento dos velhos com moças jovens. ${ }^{31}$ 
Uma vez garantida a boa herança biológica, era preciso em seguida obedecer as regras da higiene pré-natal. O que ocorreria então, conforme a descrição do Dr. Vicente Baptista, era o seguinte:

Chorou o bebê que acaba de nascer. Se a mãe foi bem orientada durante a gestação, se cumpriu as regras de puericultura pré-natal, se a gravidez transcorreu sem acidentes, ou êstes tiveram assistencia adequada, se na propria ascendencia ou na do marido não há doenças hereditarias ou familiares, se ambos não são muito jovens, nem velhos, e gozam de perfeita saude fisica e psiquica, o recemnascido deve ser sadio $[\ldots]^{32}$

Desde que todos os cuidados anteriores ao nascimento permitissem trazer à luz um recém-nascido saudável, bastaria que as mães seguissem rigorosamente os princípios da puericultura para evitar o surgimento das doenças. A eugenia e a puericultura eram, portanto, os meios de que os higienistas dispunham para intervir preventivamente na sociedade. E um aspecto-chave dessa prevenção era a aliança entre os médicos e as mães, pois eram elas que lhes dariam acesso aos domicílios, mais especificamente ao dormitório do casal, que representava o início de tudo, e ao quarto do recém-nascido. Moncorvo Filho, recorrendo a um texto datado de 1870, da autoria de Fonssagrieves, assinalava a complementaridade dos papéis da mãe e do médico e manifestava o entrave que uma mãe pouco colaboradora poderia representar no ofício do médico ou, ao contrário, o valor do seu auxílio:

Qual de nós não comprehendeu mil vezes, em sua carreira de medico a differença de assistencia que se encontra, de um lado, numa dessas mães de idéas estreitas, de preconceitos perturbadores, de exigencias irritantes, de cuidados mal dirigidos, e de outro, na que bem comprehende o seu papel, depositando firme confiança no medico, secundando-o reflectidamente, com cuidados tão intelligentes, quão dedicados? $?^{33}$

32 BAPTISTA, V. Higiene e Alimentação da criança. Rio de Janeiro: Calvino Filho, 1933.

p. 23.

33 MONCORVO FILHO, Hygiene infantil..., p. 425-426. 
Em O livro das mãezinhas, o Dr. Wladimir Piza idealizava duas medidas de governo que, conforme suas expectativas, permitiriam garantir a colaboração das mães e, assim, reduzir drasticamente o problema da mortalidade infantil: o exame médico dos noivos e a aprovação da mãe num exame cujas questões se referissem tão somente à matéria constante de seu manual. ${ }^{34}$ Para Almeida Junior e Mario Mursa, estratégia mais eficaz para enfrentar os mesmos problemas seria instituir o ensino da puericultura para as meninas desde o ensino primário. Essa seria a única maneira de torná-lo universal, como convinha. Os autores informavam que São Paulo estava à frente nesse processo, ao incluir no currículo das escolas normais o ensino de higiene infantil, embora considerassem que isso ainda não era o suficiente.

É, contudo, a Cartilha das mães, de Martinho da Rocha, o manual que melhor descreve a maneira como deveria ser a educação e as condutas da "mãe moderna". O autor criticava aquela que considerava como uma formação excessivamente humanística das moças, em detrimento da educação prática, que ele considerava mais importante e necessária para convencê-las da importância da higiene preventiva. Dizia ele: "O facto é devido, em parte, à educação das moças entre nós, a quem sobejam conhecimentos de linguas, musica e pintura, mas faltam noções rudimentares de culinaria e hygiene infantil." 35 Uma das conseqüências nefastas dessa falta de orientação mais prática era as jovens se tornarem facilmente influenciáveis pela própria mãe, comadres ou vizinhas. Grande parte dos problemas de nutrição dos bebês era reputada aos maus conselhos dessas pessoas falsamente "entendidas". Martinho da Rocha considerava tais personagens como adversárias que criavam sérios obstáculos à criação higiênica dos bebês, como se pode observar na seguinte descrição:

$\mathrm{Na}$ casa brasileira, nascida a criança, enche-se o quarto da puerpera de parentes e vizinhos, prodigos em conselhos. Além de ridicularizarem a disciplina alimentar, riem-se da balança adquirida com tanto sacrifício, baralham tudo, sem objeção da mãe fatigada e que não recebeu educação para criar seu filho. ${ }^{36}$

34 PIZA, W. O livro das mãezinhas. 3. ed. São Paulo: Departamento de Saúde do Estado de São Paulo - Seção de Propaganda e Educação Sanitária, 1940. p. 54.

35 ROCHA, J. M. Cartilha das mães. 7. ed. Rio de Janeiro: Civilização Brasileira, 1939. p. 102 .

36 Ibid., p. 160. 
Wladimir Piza era, talvez, o autor que mais enfaticamente advertia as mãezinhas quanto a esse perigo e, lançando mão de uma contra-estratégia, exortava-as a emprestar à vizinha, à prima e à amiga o seu livrinho de puericultura, como forma de salvar outras criancinhas, além do seu filhinho, dos perigos da ignorância. No entanto, o autor entendia que à mãe cabia atuar preventivamente, mas não curar. Se, apesar de ter seguido as regras da higiene infantil, a genitora observava que seu bebê parecia estar doente, não deveria tentar nada por conta própria, mas imediatamente procurar o médico, o único com a experiência e os conhecimentos necessários para intervir. Dizia ele: "Não queiram, porém, entender daquilo que só à custa de anos e anos de pacientes estudos e observações, sabem os médicos que se dedicam à clínica de crianças. ${ }^{.37}$ Os conhecimentos divulgados nos manuais de puericultura, portanto, capacitavam a mãe a prevenir o surgimento de doenças evitáveis, mas nunca a curar uma criança doente, tarefa da competência exclusiva do médico. Na eventualidade de uma doença, a mãe atuaria como enfermeira, conforme observava o Dr. Martinho da Rocha: "Convém ter como guia um medico cujas ordens cegamente cumpra." ${ }^{38}$ $\mathrm{Na}$ concepção desse autor, a boa educação da mãe-enfermeira deveria incluir um estágio em creche ou maternidade antes do casamento. Durante a gravidez, a ocupação mais recomendável para a gestante seria a leitura de compêndios de puericultura, tarefa à qual o autor recomendava que suas leitoras dedicassem meia hora por dia. No seu entender, a mãe moderna seria bem informada e prática, dispensando a vaidade e o luxo. Em suas palavras, "seria mais proveitoso que as mães no período da prenhez se entregassem ao estudo prático de puericultura em vez de perderem largo tempo no preparo do enxovalzinho superabundante de rendas e bordados". ${ }^{39}$

Os manuais de puericultura mais recentes, além dos cuidados higiênicos que se destinavam a proteger a vida e a saúde das criancinhas, passavam a dar cada vez mais espaço ao tema do desenvolvimento psicológico. Enquanto nos manuais mais antigos a parte relativa à educação costumava ocupar apenas um capítulo do compêndio, ou uma parte de um capítulo, nos mais novos os aspectos psicológicos e pedagógicos chegam a merecer uma consideração maior do que os cuidados físicos por parte dos

37 PIZA, op. cit., p. 86.

38 ROCHA, Cartilha das mães..., p. 102.

39 Ibid., p. 156. 
autores. Em Mãe e filho: noções de puericultura, por exemplo, os autores ponderavam que, embora já houvesse uma disposição positiva das mães em relação à observância dos cuidados higiênicos com seus bebês, o mesmo não se verificava com relação aos cuidados psicológicos. Configurava-se assim uma nova tarefa para os médicos e outros especialistas, a de investir na educação da mãe para que esta se ocupasse adequadamente também dos aspectos psicológicos da criação de um filho:

O mesmo não se dá com os aspectos psicológicos. Estes têm enorme importância na vida da criança, pois não só se relacionam com a própria felicidade ou infelicidade dela, como influem sobre seu organismo e com isso reforçam sua importância. Apesar dessa enorme e dupla importância dos aspectos psicológicos, a Mãe, em geral, está alheia a eles, às vezes nem ouviu falar neles. Eles não existem no espírito materno. Por isso não os sente, bem como não sente a origem psíquica de muitas das coisas de que se queixa. Quando informada a respeito, às vezes abre uns olhos "deste tamanho", de surpresa e, por vezes, infelizmente, de incredulidade. ${ }^{40}$

Era preciso, portanto, que os manuais começassem a desempenhar também o papel de abrir os olhos das mães para as questões psicológicas. Ou melhor, para ser mais fiel às palavras dos autores, urgia fazer existir no espírito materno os aspectos psicológicos, até então ausentes. Essa transformação está relacionada, por um lado, ao fato de que na década de 1950 e 1960 a tarefa de difusão dos princípios de puericultura já estava adiantada, de modo que as recomendações sobre como cuidar dos bebês já eram conhecidas e aceitas pelas mulheres às quais se destinavam os manuais, enquanto aquelas relacionadas à formação do espírito infantil permaneciam relativamente obscurecidas. Por outro lado, a ênfase nos aspectos psicológicos do desenvolvimento tornou-se possível graças à proliferação de estudos sobre o desenvolvimento infantil que se debruçaram sobre o impacto do ambiente familiar no "ajustamento emocional" das crianças.

Nikolas Rose ${ }^{41}$ explica que a Segunda Grande Guerra forneceu aos especialistas europeus diversos casos de crianças que foram denominadas como "carentes" (deprived), aquelas que, no contexto dos conflitos bélicos, eram afas-

40 AlCÂNTARA, P.; MARCONDES, E.; MACHADO, D. V. M. Mãe e filho: noções de puericultura. 3. ed. São Paulo: Saraiva, 1968. p. 4.

41 ROSE, N. Governing the soul: the shaping of the private self. 2. ed. London: Free Association Books, 1999. 
tadas dos pais e colocadas em instituições emergenciais de assistência, sendo privadas de uma convivência familiar normal. Os estudos de Anna Freud, por exemplo, foram baseados em observações de crianças nessas condições. Para o autor, o que é significativo nesses estudos é a fragilidade que atribuem à vida emocional das crianças. Meninos e meninas normais em tudo, a não ser pelo fato de terem sido surpreendidos pelas situações de estresse provocadas pela guerra - bombardeios, necessidade de ir para abrigos, condições insalubres em casa, afastamento dos pais etc. -, eram constantemente avaliados e seus comportamentos anômalos eram sistematicamente interpretados como carência, em especial do contato com a mãe. ${ }^{42}$ Nos manuais de puericultura brasileiros das décadas de 1950 e 1960, esses aspectos aparecem quando se passa, por exemplo, a atribuir à ansiedade da mãe o choro excessivo do filho e se começa a valorizar o contato corporal da mãe com o seu bebê. Essa recomendação constituía uma mudança importante, na medida em que, como se verá a seguir, nas décadas anteriores os pediatras defendiam o isolamento da criança em seu berço, do qual não deveria ser retirada a não ser para os procedimentos de higiene e alimentação.

Resumindo, a análise dos manuais consultados permite afirmar que a divulgação dos conhecimentos científicos sobre as crianças pequenas entre as mães, tal como idealizada pelos higienistas que atuaram no Brasil nas primeiras décadas do século XX, incluía, além da puericultura, princípios de eugenia e higiene pré-natal, de modo a assegurar o nascimento de bebês saudáveis. A principal tarefa das mães seria evitar o aparecimento da doença. Se, mesmo assim, surgisse a moléstia, a genitora deveria estar em condições de atuar como mãe-enfermeira, auxiliando o médico e seguindo sem hesitações, à risca, todos os procedimentos indicados pelo doutor. Já nos manuais publicados a partir de meados da década de 40 começam a aparecer, para além da preocupação com a saúde da população infantil, os esforços dos especialistas para divulgar entre as mães informações sobre o desenvolvimento psicológico das crianças, de modo que os manuais passam a exercer um governo mais detalhado e mais profundo da família. Embora os compêndios mais antigos já tivessem uma preocupação com a educação, pensada sobretudo em termos da formação dos bons hábitos desde o nascimento, as pesquisas sobre o desenvolvimento psicológico da infância permitiram detalhar cada vez melhor os processos de formação da

42 ROSE, op. cit., p. 169. 
personalidade a partir das influências do meio social. A família, ambiente da socialização inicial da criança, e sobretudo a mãe, geralmente a responsável por dispensar os primeiros e decisivos cuidados ao filho, começavam a ser advertidas a observar não apenas as condições higiênicas do lar, mas também suas condições psicológicas, de modo a propiciar um ambiente harmônico e educativo para seus filhos.

\section{Recomendações relacionadas à gestação, ao parto e aos primeiros cuidados com os bebês}

De acordo com os estudos de Gondra e Jurandir Freire Costa ${ }^{43}$, entre outros autores, parte importante da tarefa de sanear o Brasil, a que se dispuseram os médicos higienistas a partir da segunda metade do século XIX, consistia em fazer com que as mães se convencessem da importância de cuidar, elas mesmas, de seus filhos. O bom exercício da maternidade era valorizado pelo seu alto valor patriótico. Em seus discursos, os doutores afirmavam que apenas as mães estavam em condições de desempenhar adequadamente o papel de primeiras educadoras dos cidadãos da pátria, bem como de velar pelo seu desenvolvimento saudável. Simultaneamente, procuravam mostrar que era apenas por meio da maternidade que as senhoras encontrariam sua plena realização como mulheres. Para os autores do Livro das mães, "ao se tornar mãe a mulher fica com o organismo mais completo e com melhor saúde" ${ }^{44}$. De maneira similar, o doutor Waldemar Lages afirmava: "É comum observar-se que grande número de mulheres, antes achacadas e sempre doentes, durante a gravidez passa a melhor fase de saúde da sua vida." ${ }^{45}$ Sendo assim, as mulheres eram levadas a aceitar o único papel socialmente valorizado para elas, confiantes de que assim estariam assumindo sua mais nobre missão social, aquela para a qual eram insubstituíveis, e ainda a que lhes permitiria experimentar um estado de maior completude e vitalidade. A mãe, portanto, era, como ainda é, retratada como uma mulher superior.

43 GONDRA, op. cit.; e COSTA, op. cit.

44 VASCONCELOS, F.; LOPES, C. A. Livro das mães. 6. ed. Rio de Janeiro: Departamento Nacional da Criança, 1962. p. 70.

45 LAGES, W. Como proteger seu filho: problemas de maior freqüência na assistência à infância. Rio de Janeiro: Instituto de Resseguros do Brasil, 1955. p. 11. 
Nos capítulos dos manuais referentes aos cuidados pré-natais, as mulheres eram encorajadas a confiar seus corpos ao médico pelo menos desde o início da gestação, sendo que o ideal era fazê-lo antes mesmo da concepção, por meio dos exames médicos pré-nupciais, conforme já se mencionou. Quanto mais recente o manual, mais numerosas são as consultas recomendadas, bem como os exames indicados. O doutor Alcântara ${ }^{46}$ procurava inclusive disciplinar a preparação para a consulta, recomendando que nesse dia a mulher tomasse banho, usasse roupa limpa, esvaziasse o intestino e levasse urina para exame.

Quanto ao estilo de vida recomendado para a gestante, esse era em tudo coincidente com o da boa dona de casa. As futuras mães deveriam dedicar-se exclusivamente aos cuidados com a casa e a família. Laport ${ }^{47}$ afirmava que a gravidez não era doença e não tornava a mulher inválida. Recomendava às mulheres que vivessem de maneira saudável, ativa e alegre esse período. A gestante deveria levar uma vida calma, de preferência buscar o isolamento social e preservar-se de conversas que poderiam trazer inquietações. No texto de Freire de Vasconcelos e Carlos A. Lopes, médicos puericultores do Departamento Nacional da Criança, surgia o marido, em geral ausente dos textos dos manuais. Diziam os doutores: "Ao marido cabe, nessa fase, auxiliar a esposa para que seja mantido o ambiente de calma indispensável nessa ocasião."

Embora passeios ao ar livre e atividades físicas moderadas - tais como as requeridas para as lides domésticas - fossem indicados, o trabalho fora de casa, a circulação social e a prática de esportes eram apresentadas como fatores de risco. O Dr. Barros Filho escrevia que "os serviços caseiros, quando não exigem esforço demasiado, devem continuar a ser desempenhados, pois além de serem úteis por constituírem exercícios leves, proporcionam entretenimento e descanso ao espírito"49. Por outro lado, o trabalho fora de casa podia cansar excessivamente, além de trazer riscos de contaminação, sobretudo o ofício exercido nas fábricas. Segundo o Dr. Martagão Gesteira, “[...] o trabalho prolongado da mulher, qualquer que ele seja, nas últimas semanas de gravidez, acarretando a estafa materna, pode ser um fator de mortinatalidade

46 ALCÂNTARA, Pedro de. Higiene da primeira infância. 3. ed. São Paulo: Companhia Editora Nacional, 1945.

47 LAPORT, F. A.B.C. das mães. Rio de Janeiro/São Paulo: Freitas Bastos, 1941.

48 VASCONCELOS, F.; LOPES, C. A. op. cit., p. 70.

49 BARROS FILHO, J. M. O médico e a criança: estudos de puericultura e eugenia. Prefácio do Dr. Margarido Filho. São Paulo: Empresa Gráfica da Revista dos Tribunais, 1940. p. 72. 
e é freqüentemente de desenvolvimento precário do produto" 50 . A vida social costumava pôr a mulher em contato com notícias que poderiam impressioná-la negativamente. Além disso, o figurino exigido nos eventos sociais era pouco recomendável à gestante, que deveria dar preferência às roupas largas e aos sapatos de salto baixo. Para distraírem-se, as gestantes deveriam entregar-se a leituras leves ou ao estudo de manuais de puericultura.

Quanto à higiene corporal, os médicos recomendavam banhos mornos e indicavam uma diversidade de cuidados com os seios, com vistas a prepará-los para a amamentação: lavar, besuntar com diferentes substâncias, friccionar, fazer exercícios e/ou massagear para torná-los salientes, o que facilitaria a amamentação. Proibiam o uso de banheiras e bidês nas últimas semanas de gestação, porque, segundo Freire de Vasconcelos, poderiam "permitir a penetração de germes nos órgãos genitais" 51 .

Nos conselhos sobre a alimentação da gestante, chama a atenção a diversidade de opiniões. Enquanto o Dr. Waldemar Lages afirmava que a gestante " pode comer de tudo que lhe apetecer e ingerir ou usar a medicação que mais the convier. Nada, nesse particular, pode prejudicar a criança" 52 , outros indicavam uma série de restrições, sugeriam substituições e alterações no preparo dos pratos convencionais ou solicitavam o aumento do consumo de algum tipo de alimento considerado importante, em geral o leite. ${ }^{53}$ Os autores eram unânimes, contudo, ao indicar a abstenção do álcool e do fumo e em condenar um hábito tradicional aparentemente bastante difundido, que consistia em fazer a gestante ou lactante beber cerveja preta para aumentar a produção do leite.

Tendo em vista a diversidade de cuidados que as gestantes deveriam ter consigo próprias durante a gestação, assim como a variedade das situações a evitar, observa-se que os médicos procuravam tomar conta de toda a vida da gestante: suas tarefas, suas distrações, seus cuidados íntimos, suas companhias e até seus pensamentos. Tudo era codificado pelos pediatras, de modo que, se as recomendações fossem seguidas à risca, a vida da mulher durante os nove meses de espera passava a ser inteiramente dedicada à gestação e vigiada pelo especialista.

50 GESTEIRA, M. Puericultura: higiene alimentar e social da criança. Rio de Janeiro: Pan-Americana, 1943. p. 344.

51 VASCONCELOS; LOPES, op. cit., p. 68.

52 LAGES, op. cit. p. 10.

53 Indicações desse tipo aparecem em Higiene da primeira infância (1945), da autoria de Pedro de Alcântara; O médico e a criança, de Barros Filho (1940); e Livro das mamães, de Almeida Junior e Mário Mursa (1938), entre outros. 
A necessidade de se confiar ao médico era ainda mais enfatizada nas descrições do parto, descrito como uma viagem extremamente perigosa para o recém-nascido, seguida de uma adaptação difícil do organismo ao ambiente externo. Em Puericultura, de Martagão Gesteira, encontra-se um bom exemplo desse tipo de relato:

\begin{abstract}
Nenhuma época é mais perigosa do que essas primeiras horas imediatas à travessia tormentosa que acabou de fazer o recemnascido, ameaçado pelas conseqüências do traumatismo por que acabou de passar e pela brusca e radical mudança que sofre a sua fisiologia, desde que mergulha no ambiente exterior e do organismo materno se desprende. E para o aumento de tais perigos concorre ainda aquela extrema fragilidade que, como vimos no capítulo anterior, apresenta o menino ao nascer. Nenhum ser vivo se mostra mais frágil e mais desprotegido ao nascer do que o filho do homem, que tem a pretensão de considerar-se o "rei da criação". É indispensável assisti-lo e prestar-lhe especiais cuidados nessas primeiras horas, afim de serem evitadas graves conseqüências..$^{54}$
\end{abstract}

O nascimento era descrito, portanto, como uma aventura, na qual o próprio corpo da mãe - como passagem - e o meio externo constituíam ameaças à vida e à saúde do bebê, enquanto os procedimentos científicos executados pelo médico, de preferência em maternidade, eram referidos como os melhores recursos de que se dispunha para neutralizar os perigos e aumentar as chances de sobrevivência do neonato.

Após a narrativa sobre o parto e a descrição do aspecto do bebê ao nascer, os médicos dedicavam-se ao aspecto da puericultura tido como prioritário em todos os manuais, o aleitamento materno. Segundo os autores, estudos estatísticos indicavam que as crianças alimentadas artificialmente corriam mais riscos do que as que recebiam leite materno. Na Cartilha das mães, Martinho da Rocha explicava que, "na Alemanha, onde todos se empenham por conhecer hygiene infantil, a mortalidade dos bebês alimentados em mamadeira é, mesmo assim, cinco vezes maior do que a dos criados ao seio" 55 . Acrescentava ainda: "Entre nós, a cifra supera essa proporção. Dos 200.000 bebês nascidos em S. Paulo em 1937 setenta mil morreram antes de completar o primeiro ano de vida!" 56

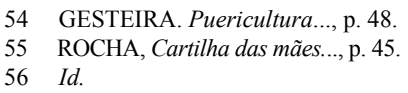


Pretendendo contribuir para a diminuição da mortalidade infantil, os higienistas elegeram, portanto, a amamentação como um problema de governo. Era preciso fazer com que as mães se dispusessem a dar de mamar a seus bebês. Tratava-se de um problema de biopolítica que foi enfrentado de diversas maneiras, entre as quais mediante a distribuição de manuais de puericultura entre os jovens casais no momento em que se dirigiam ao cartório para registrar seus bebês, como ocorreu com O livro das mãezinhas. $\mathrm{Na}$ introdução ao volume, o autor manifestava sua esperança afirmando:

Se os que vão receber este livrinho aplicarem bem os conselhos que ele contém, temos a certeza de que as cifras de mortalidade das crianças, entre nós, cairão rapidamente. $\mathrm{E}$ assim, dentro em breve, teremos afastado dos nossos olhos esse fantasma terrível, que penetra nos lares paulistas e rouba do regaço de mães amantíssimas aqueles que seriam os continuadores das nossas tradições e os propugnadores do nosso progresso. ${ }^{57}$

Nos seus manuais, os pediatras lançaram mão de argumentos positivos e negativos para atingir esse objetivo. Por um lado, tentavam mostrar às mães que amamentar não era necessariamente um fardo, não impunha tantas restrições como se costumava acreditar e poderia até ser uma fonte de prazer para a mãe e o bebê. Por outro lado, procuravam fazer se sentirem culpadas as mães que negassem o seio aos seus filhos. Nos textos examinados, o aleitamento materno era considerado como algo determinado pela natureza, extremamente positivo e desejável. Muitos benefícios para a saúde do bebê eram associados à amamentação. Tratava-se do alimento mais adaptado ao organismo do recém-nascido, de modo que permitia uma digestão fácil; era capaz de proteger a criança contra uma série de doenças, funcionando como uma vacina natural; evitava a contaminação do leite, uma vez que o alimento passava diretamente do peito à boca do bebê. Justamente porque prevenia contra doenças e não sobrecarregava o organismo infantil, permitia reduzir drasticamente os índices de mortalidade infantil. A citação a seguir oferece um exemplo de argumento empregado pelos pediatras em defesa do leite materno:

57 PIZA, op. cit., sem indicação do número de página. 
O leite humano, nos primeiros meses de vida, é insubstituível. Sua composição, ótima para as necessidades da criança, apresenta tudo quanto esta precisa, nas melhores proporções; sua quantidade corresponde exactamente ao que convem; sua temperatura concorda com a da criança; nenhum outro alimento se ajusta tão bem à capacidade digestiva do tubo gastro-intestinal do lactante, donde a facilidade e economia com que é aproveitado. ${ }^{58}$

Listam-se ainda, nos textos examinados, outras vantagens da amamentação, com o claro objetivo de torná-la atrativa para a mulher. Promete-se maior afeição do bebê pela mãe que amamenta, mais conforto, praticidade e até saúde e beleza para a mulher. Os pediatras afirmavam que a amamentação fortalecia o vínculo afetivo entre a mãe e o bebê; era benéfica à saúde das mães, melhorando o apetite e retardando a velhice, e era mais prática do que o preparo cuidadoso das mamadeiras. O doutor Vicente Baptista afirmava, por exemplo, que:

Com o leite materno desaparecem, como por encanto, todos os empecilhos próprios do preparo da mamadeira, o alimento sempre pronto, com temperatura precisa, ótimo, sem germes e substancias nocivas, inalterável, pode, a qualquer momento e sem mais cuidado, ser oferecido ao bebê. A amamentação com técnica é suavíssima e não estorva as ocupações domésticas da mãe nem suas diversões. ${ }^{59}$

Os pediatras apresentavam-se, portanto, como aliados das mulheres, que poderiam ensiná-las o caminho de uma maternidade feliz, em que seria possível conciliar os melhores cuidados para o bebê com o mínimo de aborrecimentos. A mãe higiênica poderia vangloriar-se de fazer o máximo por seu bebê quase sem renunciar aos seus divertimentos. Desde que confiasse em seu médico, poderia ter a satisfação de ver crescer saudáveis os seus filhos. Simultaneamente, estaria contribuindo para a prosperidade do país, oferecendo-lhes cidadãos bem constituídos. Contudo, aquelas que, por ignorância ou egoísmo, negassem o leite materno aos seus bebês, eram consideradas merecedoras de desprezo e ameaçadas de serem rejeitadas pelos próprios filhos, com os quais não conseguiriam estabelecer um vínculo afetivo estreito. Nas palavras do Dr. Barros Filho:

58 ALMEIDA JUNIOR, A; MURSA, M. Noções de puericultura para as mães ..., p. 46

59 BAPTISTA, V. Higiene e alimentação da criança. Rio de Janeiro: Calvino Filho, 1933.

p. 67. 
É nossa obrigação, também, combater o egoísmo de muitas mães, principalmente nas classes abastadas, que não amamentam para não deixar a vida mundana a que estão habituadas ou que não amamentam pelo temor de perder suas linhas de elegância ou a beleza dos seus seios. Estas, não podem merecer o nome de MÃE, e os laços e amizade entre mãe e filho tendem a afrouxar-se fatalmente. ${ }^{60}$

Nem sempre, porém, a recusa em amamentar era devida à má vontade das mães, havia outros impedimentos. Segundo os autores, a grande maioria das mães podia amamentar desde que acreditasse em sua capacidade natural para isso e não desse ouvido às pessoas - amigas, avós, comadres etc. - que eventualmente lhes dissessem que seu leite era insuficiente ou fraco. Em todo caso, apenas o médico estava em condições de decidir se uma criança precisava ser desmamada ou receber alimentação artificial complementar. Nesse aspecto, como em todos os outros relacionados aos cuidados com os bebês, conselhos de outras mulheres eram entendidos como ameaças à saúde da criança. O livro das mãezinhas é, a esse respeito, bastante persuasivo, dirigindo-se diretamente à consciência das jovens mães:

Escolhe entre os conselhos das amigas que, embora com boa intenção, te ensinam o que não sabem porque não estudaram, e as recomendações dos especialistas que passam a vida tratando de crianças, do hospital para o laboratório, e toma o caminho que tua inteligência te indicar. Mas pensa bem antes! Teu filho será amanhã o prêmio dos teus esforços, ou o castigo de sua desorientação; tudo dependerá do modo pelo qual o criares. ${ }^{61}$

Para os pediatras, os principais obstáculos à amamentação não eram, portanto, de origem orgânica, mas de origem social. Para as mães pobres, havia ainda a exigência do retorno ao trabalho, que impunha o fim do aleitamento. Como forma de evitar esse problema, sugeria-se a criação de uma lei que garantisse às mães trabalhadoras o direito de continuar amamentando ou então a ampliação do número de creches próximas aos locais de trabalho, onde as crianças pudessem ficar adequadamente instaladas enquanto as mães trabalhavam e pudessem ser amamentadas nos intervalos. Assim, enquanto as mães ricas que se recusavam a aleitar eram repudiadas

60 BARROS FILHO, J. M. O médico e a criança ..., p. 148.

61 PIZA, O livro das mãezinhas, ... p. 6. 
como vaidosas e egoístas, as mulheres pobres recebiam a solidariedade e o apoio dos médicos, que defendiam inclusive a alteração da lei, de modo que mães e bebês pudessem ser melhor assistidos.

Embora um argumento importante em favor da amamentação afirmasse que se tratava de um ato determinado pela natureza, uma série de regras higiênicas ditadas pelos pediatras regulavam essa prática, de modo que a puericultura apropriou-se do aleitamento para disciplinar as mães e os bebês. Por um lado, diversos pediatras procuravam garantir às mulheres que se dispusessem a amamentar a liberdade de se alimentarem segundo seus hábitos e desejos. Recomendavam apenas a ingestão de uma quantidade maior de líquidos ou de leite. Afirmavam ainda que a ingestão de remédios ou as emoções fortes não alteravam significativamente a composição do leite, envenenando-o, como se costumava acreditar no passado. Nesse sentido, portanto, os pediatras procuravam facilitar as coisas para as mães.

Por outro lado, no que se referiam aos horários, os especialistas eram inflexíveis. Embora houvesse variações entre os manuais no que se refere ao momento em que a criança deveria ser amamentada pela primeira vez e em relação ao período em que o regime definitivo seria estabelecido, havia o consenso de que por volta do final do primeiro mês todos os bebês já deveriam estar habituados a um regime de seis mamadas diárias, a intervalos de três horas e sem mamadas noturnas. Também era opinião consensual que durante a noite a mãe não deveria amamentar, sob pena de ficar exausta e educar mal o seu filho. Segundo Wladimir Piza:

Ao fim de algum tempo está ela (a criança) perfeitamente habituada ao horário; mama e logo após dorme, para só acordar de novo na hora de mamar. Tornar-se-á disciplinada desde o nascimento e não dará aborrecimentos aos pais; aprenderá desde o berço que, nesta vida, só se tem o direito de exigir o que nos pertence e nas ocasiões oportunas: e essa disciplina influirá beneficamente no seu sistema nervoso. ${ }^{62}$

A duração da mamada também era estipulada por diversos pediatras. O bebê mamaria por quinze ou vinte minutos, não mais do que isso. 
Os pediatras podiam aceitar que a mãe e o bebê experimentassem prazer na amamentação, inclusive referiam-se ao prazer como um dos atrativos para encorajar as mulheres ao aleitamento. Admitiam-no, entretanto, apenas enquanto se tratasse de realmente nutrir o bebê. Depois disso, era preciso interromper a mamada, para não prejudicar o seio da mãe e não deixar o bebê mal acostumado. Dar de mamar ao bebê para acalmá-lo era considerado como um mau hábito, recurso meio imoral. Havia, porém, pediatras mais liberais, os quais entendiam que o próprio bebê estabeleceria a duração da mamada. O período estabelecido de três horas entre as mamadas era recomendado para permitir que a criança digerisse completamente cada refeição. No entanto, enquanto alguns autores recomendavam que se acordasse o bebê para mamar nos horários estabelecidos, outros entendiam que isso não era necessário, considerando mais importante garantir que houvesse seis refeições diárias do que cumprir rigidamente o horário. Os pediatras tratavam ainda de orientar as mães sobre as posições corretas para amamentar, sobre a higienização dos seios a cada mamada e precauções para evitar o contágio da criança caso a própria mãe estivesse doente. Em diversos manuais essas orientações eram acompanhadas de fotografias de mães amamentando corretamente, com o objetivo de demonstrar mais claramente os procedimentos sugeridos.

Enfim, as considerações anteriores procuraram chamar a atenção para algumas das recomendações mais recorrentes nos manuais sobre o aleitamento materno, a gestação e o parto. Muito poderia ser escrito ainda sobre as restrições feitas pelos pediatras em relação ao aleitamento mercenário, em que a mãe, impossibilitada de amamentar, contratava outra mulher para aleitar o seu filho. Há ainda nos manuais farto material para ser analisado no que diz respeito à alimentação artificial do lactente, cujo exame não caberia, contudo, nos limites deste artigo. Sendo assim, procurou-se privilegiar os textos relacionados ao disciplinamento de alguns dos aspectos mais íntimos da relação mãe - bebê, os quais, no entanto, transformaram-se em questões de interesse público no período considerado, a partir da atuação dos pediatras higienistas. 


\section{Considerações finais}

Dirigindo-se às mães, em seu manual de puericultura, Wladimir Piza sintetizava em 1940 o significado político da aliança entre as mães e os pediatras:

O governo de São Paulo se interessa pelo teu filho. Ele vê, nessa criança que dorme agora no berço ao lado da tua cama, um cidadão do futuro, cheio de amor pela sua terra, que ele há de engrandecer e honrar.

Leva o teu filho ao Centro de Saúde mais próximo da tua casa e segue com atenção os conselhos que vais receber dos que, tendo estudado bem a arte de curar, poderão, por isso mesmo, impedir que a doença destrua essa vida, que hoje está cercada pelo halo rebrilhante da esperança. ${ }^{63}$

Entre os recursos empregados para firmar essa aliança, os manuais de puericultura merecem ser considerados. Dirigidos não apenas às mães que acabavam de dar à luz seus bebês, mas também às prováveis futuras mães que freqüentavam os cursos de puericultura das escolas públicas brasileiras, procuravam simultaneamente informar e converter cada mulher numa mãe higiênica ou, segundo a expressão de Martinho da Rocha, numa "mãe-enfermeira". Devotada, habilidosa, determinada e obediente, a mãe ideal seria capaz de descrever minuciosamente ao pediatra tudo o que pudera observar em seu filho e, em seguida, com o mesmo detalhamento, trataria de cumprir suas recomendações.

Sendo assim, contar a história do governo da relação mãe - bebê a partir da análise dos manuais de puericultura corresponde, num certo sentido, a contar a história da conquista dos campo da maternidade e da infância pelos médicos, a ponto de atualmente esses especialistas poderem deixar a tarefa de escrever os guias maternos para as próprias mães, com a segurança de que essas serão capazes de reproduzir e defender os princípios mais importantes da pediatria moderna, incluindo a amamentação. Além disso, atualmente os doutores já não precisam temer os "excessos do amor materno" nem a ajuda das avós, na medida em que esses já passaram por um rigoroso processo de higienização, tornando-se, enfim, aliados dos pediatras no governo da relação mãe - bebê. 